\title{
Driving parameters of biogenic volatile organic compounds and consequences on new particle formation observed at an Eastern 5 Mediterranean background site
}

Cécile Debevec $^{1}$, Stéphane Sauvage ${ }^{1}$, Valérie Gros ${ }^{2}$, Karine Sellegri ${ }^{3}$, Jean Sciare ${ }^{4,2}$, Michael Pikridas ${ }^{4}$, Iasonas Stavroulas ${ }^{4}$, Thierry Leonardis ${ }^{1}$, Vincent Gaudion ${ }^{1}$, Laurence Depelchin ${ }^{1}$, Isabelle Fronval ${ }^{1}$, Roland Sarda-Esteve ${ }^{2}$, Dominique Baisnée ${ }^{2}$, Bernard Bonsang ${ }^{2}$, Chrysanthos Savvides, Mihalis Vrekoussis $^{4,6}$, Nadine Locoge ${ }^{1}$.

10 1 Lille Douai, Univ. Lille, SAGE - Département Sciences de l'Atmosphère et Génie de l'Environnement, 59000 Lille, France

${ }^{2}$ Equipe CAE, Laboratoire des Sciences du Climat et de l'Environnement (LSCE), Unité Mixte CEA-CNRS-UVSQ, Gif sur Yvette, 91190, France

${ }^{3}$ Laboratoire de Météorologie Physique (LaMP), CNRS UMR 6016, Université Blaise Pascal, Aubière, 60026, France

${ }^{4}$ Energy, Environment and Water Research Centre, the Cyprus Institute (CyI), Nicosia, 2121, Cyprus

$15{ }^{5}$ Department of Labour Inspection (DLI), Ministry of Labour, Welfare and Social Insurance, Nicosia, 1493, Cyprus

${ }^{6}$ Institute of Environmental Physics (IUP), University of Bremen, Bremen, 28359, Germany

Correspondence to: Stéphane Sauvage (stephane.sauvage@imt-lille-douai.fr) - Cecile Debevec (cecile.debevec@imt-lilledouai.fr) 
SI-1 Agreement between on-line and off-line measurements of $\alpha$-pinene, $\beta$-pinene and the sum of monoterpenes
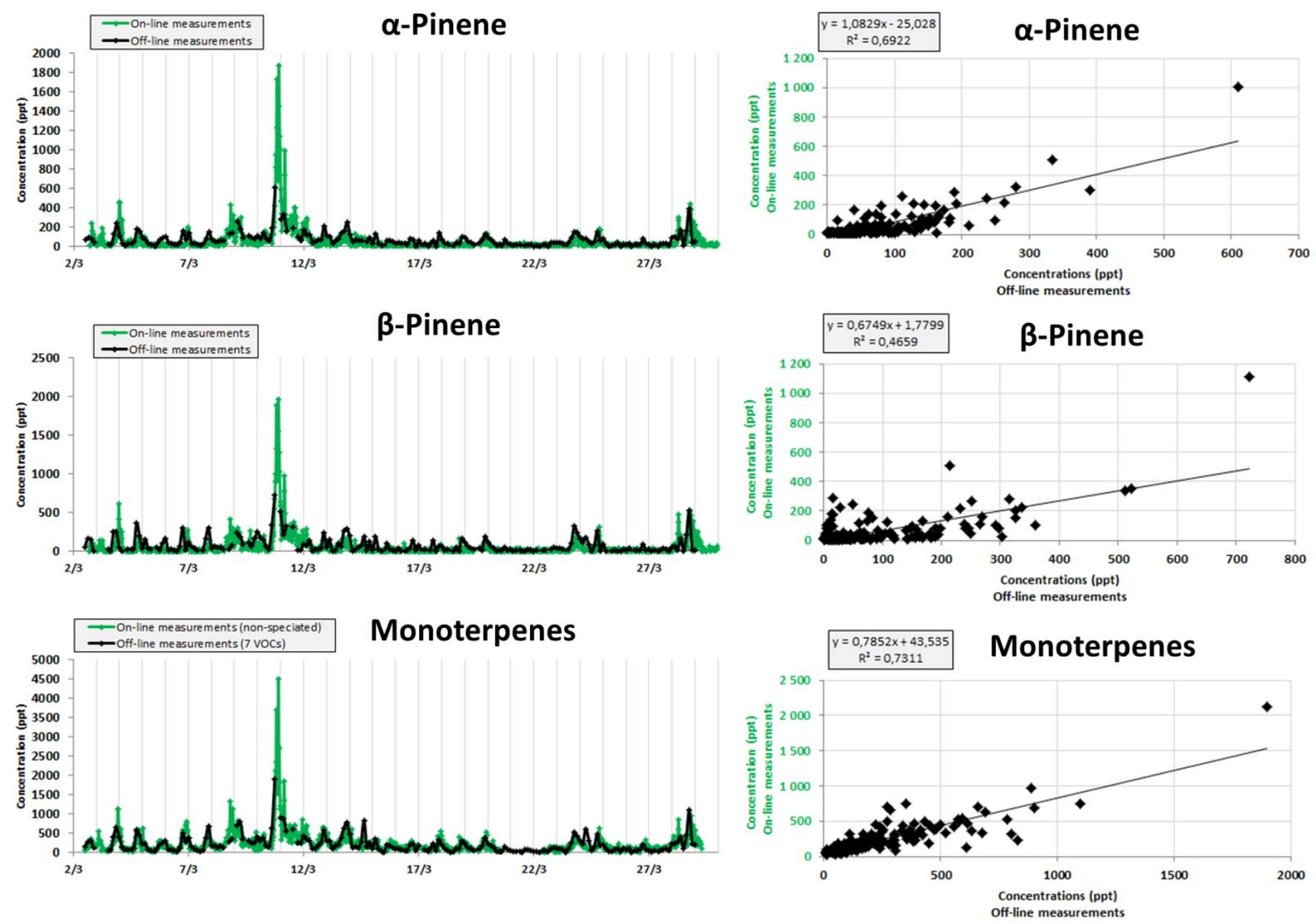
SI-2 Agreement between on-line and off-line measurements of acetaldehyde, acetone and MEK
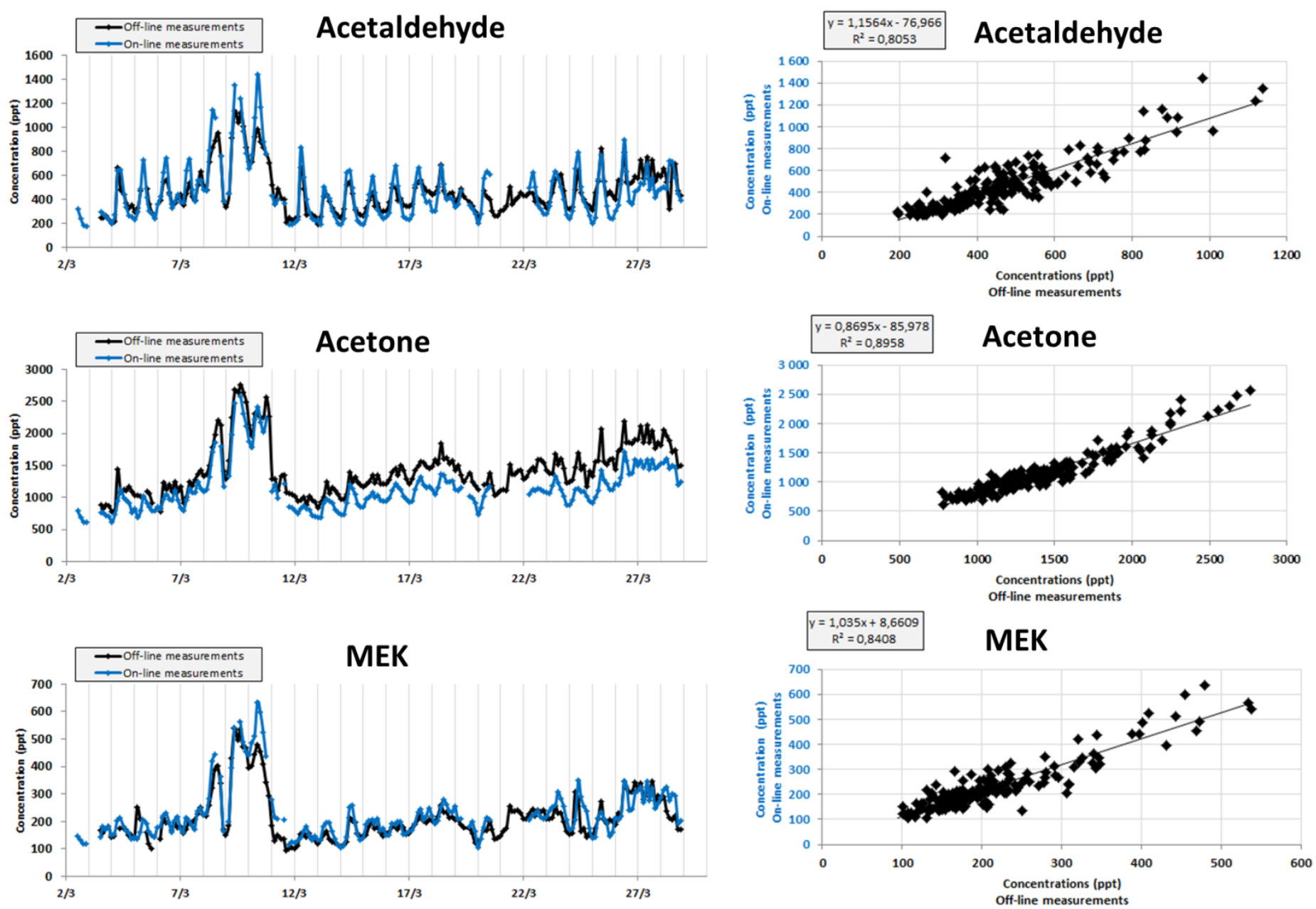